Review

\title{
Expert Control Systems for Maximum Power Point Tracking in a Wind Turbine with PMSG: State of the Art
}

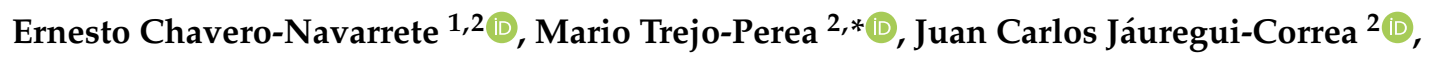 \\ Roberto Valentín Carrillo-Serrano ${ }^{2} \mathbb{D}$ and José Gabriel Ríos-Moreno ${ }^{2} \mathbb{C}$ \\ 1 Centro de Tecnología Avanzada CIATEQ AC, Querétaro 76150, Mexico; ernesto.chavero@ciateq.mx \\ 2 Facultad de Ingeniería UAQ, Universidad Autónoma de Querétaro, Querétaro 76010, Mexico; \\ jc.jauregui@uaq.mx (J.C.J.-C.); roberto.carrillo@uaq.mx (R.V.C.-S.); riosg@uaq.mx (J.G.R.-M.) \\ * Correspondence: mtp@uaq.mx; Tel.: +55-442-192-12-00 (ext. 6064)
}

Received: 17 April 2019; Accepted: 11 June 2019; Published: 17 June 2019

Featured Application: The article highlights a trend in the use of Maximum Power Point Tracking controllers with Expert Systems for wind turbines, due to the complexity of the mathematical models and the non-linearity of the system.

\begin{abstract}
Wind power is a renewable energy source that has been developed in recent years. Large turbines are increasingly seen. The advantage of generating electrical power in this way is that it can be connected to the grid, making it an economical and easily available source of energy. The fundamental problem of a wind turbine is the randomness in a wide range of wind speeds that determine the electrical energy generated, as well as abrupt changes in wind speed that make the system unstable and unsafe. A conventional control system based on a mathematical model is effective with moderate disturbances, but slow with very large oscillations such as those produced by turbulence. To solve this problem, expert control systems (ECS) are proposed, which are based on human experience and an adequate management of stored information of each of its variables, providing a way to determine solutions. This revision of recent years, mentions the expert systems developed to obtain the point of maximum power generation in a wind turbine with permanent magnet synchronous generator (PMSG) and, therefore, offers a control solution that adapts to the specifications of any wind turbine.
\end{abstract}

Keywords: control systems; wind power generation; artificial neural network; fuzzy logic control; intelligent search algorithms

\section{Introduction}

The growth of a country depends on its work centers, the generation of employment, the development of their companies and services. Electricity is indispensable for each of these activities, which is why it is essential to increase energy generation and satisfy the growing demand. At the same time, it is necessary to resort to clean and renewable energies with minimal environmental damage [1].

Wind energy, for example, has achieved significant technological advances in safety and efficiency. International organizations such as The Global Wind Energy Council (GWEC) have reported that in more than 90 countries around $54 \mathrm{GW}$ of wind energy have been installed in 2017, increasing the accumulated capacity to $486.8 \mathrm{GW}, 12.6 \%$ more than in 2016 [2]. The size of wind turbines has increased in recent years; the commonly used wind turbine has a diameter of the sweeping area of $125 \mathrm{~m}$ able to produce up to $7.5 \mathrm{MW}$ [3]. However, since 2016 it is more common to see wind turbines with a nominal 
power of 9.5 MW [4]. However, model V164-10, capable of generating up to $10 \mathrm{MW}$, is now available for sale and can be delivered for commercial installation after 2021 [5].

Unlike other sources of energy, the wind is not controllable, varies in time and space, and is a non-uniform and transient resource. Because man cannot control the randomness of the wind, it is necessary to use a variable speed turbine, thus making the most of this natural resource at all times. Since these turbines can change their rotation speed, to follow changes in wind speed, it follows that for each wind speed there is an ideal rotation speed, which is called optimal Tip Speed Ratio (TSR), and is different for each wind turbine [6]. The complexity of modern wind turbines forces that its control systems ensure safe and efficient operation. The angle of the blade, torque of generator and the grid side controller are the main parameters that must be controlled. The objective of these control systems is to maximize energy production, mitigate static and dynamic mechanical loads and ensure a continuous supply of energy to the grid [7].

The rotation of the blade to modify the angle of incidence between the direction of the wind and the blade, can be done with a shared conductor for all the blades, or independently. The angle is zero when the wind speed is less than nominal and increases when the wind speed exceeds nominal value. This pitch control can reduce the load on the drive train and the structure of the tower, which leads to a longer installation life [8,9]. The torque control of the generator allows varying the speed of the turbine rotor applying the strategy of point of maximum power (MPPT), to extract as much energy as possible from the wind flow. With changes in wind speed, the rotor torque increases or decreases, so the generator torque must be the shock absorber for the turbine to turn at optimum speed [7]. The grid-side controller controls the electronic switching of the stator and rotor voltages to produce the desired voltage frequencies, therefore, it controls the active and reactive power supplied to the network [10].

The definition of the control objectives depends on the operating regions of the wind turbine. These are closely related to the wind speed and one can identify four operating regions according to the wind speed. Region I represents the wind speed that the rotor cannot move, so the rotation speed is zero. When the rotor begins to rotate, it enters region II, and this region is limited by the starting speed and wind speed where the generator rotates at its nominal speed. The objective of control in this region is to maximize energy production through MPPT strategies. Region III starts from the nominal speed to the stopping speed, which is the design speed limit and is required to stop rotation for safety. To maintain the constant nominal rotation speed, the pitch control is used. However, MPPT control is also used in this region to smooth out abrupt changes in wind speed, where the mechanical restrictions of the pitch system do not allow for a rapid response. Finally, there is region IV, where the wind turbine must be stopped, even with a mechanical brake [11,12].

To operate in variable speed conditions a wind power system needs a generator that can work in these conditions. The first wind turbines did not have torque control and used a squirrel-cage induction generator (SCIG) connected directly to the grid, so the torque of the generator was not controllable and the speed of the generator was linked to the frequency of the net. Currently, most generators use variable speed operations, namely the Dual Feed Induction Generator (DFIG) and the Permanent Magnet Synchronous Generator (PMSG) [7].

Among the electric generators, the PMSG is preferred due to its high efficiency, reliability, power density, gearless construction, and light weight and self-excitation characteristics. Among various types of gear train coupling, the gearless or directly allied permanent magnet type wind generators are more popular nowadays in the wind energy market in on-shore application [13]. The control of the PMSG to achieve the maximum power point can be done by varying its load using an electronic power interface circuit. The interconnection can be done through a back-to-back converter or through a three-phase diode rectifier connected to a boost converter [14].

The objective of this work is to perform an analysis of the MPPT control systems with PMSG generators. According to the reviewed literature, it is stated that an MPPT controller is the most important part of the control in a wind turbine, since the turbines are designed to work most of the 
time in regions II and III and in both regions an MPPT controller it is required. On the other hand, the PMSG is the most used. The MPPT algorithms have been classified according to the maximization of the captured power, the MPPT algorithms are categorized into Indirect Power Controllers (IPC) and Direct Power Controllers (DPC). The IPC maximizes the captured mechanical wind energy while the DPC directly maximizes the electrical power output [15]. The main MPPT algorithms that are widely used include the tip speed ratio (TSR), power signal feedback control (PSF), optimal torque (OPC), Search for slope ascent (HCS), perturbation and observation method (P\&O), incremental conductance and optimal base relation (ORB), as well as computer techniques developed with expert systems, such as fuzzy logic and neural networks [10]. Energy storage too can control and reduce power fluctuations, enhances the electric system flexibility, and enables the storage and dispatching of the electricity generated. Different storage technologies are used in electric power systems. They can be electrochemical (Batteries), mechanical (Flywheel energy storage) or electrical (Super capacitor energy storage). Several types of batteries can be used: NickeleCadmium (NieCd), NickeleZinc (NieZn) or lead acid. The battery must have some important characteristics such as high charge or discharge efficiency, low self-discharge and long cycle life. The flywheel includes a cylinder with a shaft connected to an electrical generator and helps to maintain the power generation constant, as long as the wind power is sufficient. Inertial energy is stored to cushion power changes of the wind generator; it is necessary to know the reference speed, which ensures that the system transfers the required energy by the load at any time. Super capacitors are used to suppress fast wind power fluctuations but at a minor scale. Thus, they can be considered only as a support for wind turbines systems and are generally combined with a battery system [16].

The analysis carried out in the literature indicates a trend in the use of MPPT controllers with ECS for wind turbines, due to the complexity of the mathematical models and the non-linearity of the system. In this paper, we present a summary of control algorithms developed for ECS in the last 4 years. The objective is to guide the reader in the use of expert systems, since these are a solution for the control of wind turbines that do not have detailed specifications or do not have the economic resources to implement an adequate instrumentation. The strategy of ECS is based on deducting data with laws of probability for the prediction of climatic conditions, search of the optimal solution in different conditions and the handling of data to find patterns of behavior of its variables [17].

\section{Wind Turbine Generator Systems}

The turbines are composed of the rotor of blades that convert the kinetic energy of the wind into mechanical energy, the gearbox that multiplies the speed of the rotor and transmits it to the axis of rotation of the generator, the electric generator, control system and the instrumentation [18]. Figure 1 shows a general diagram of wind turbine.

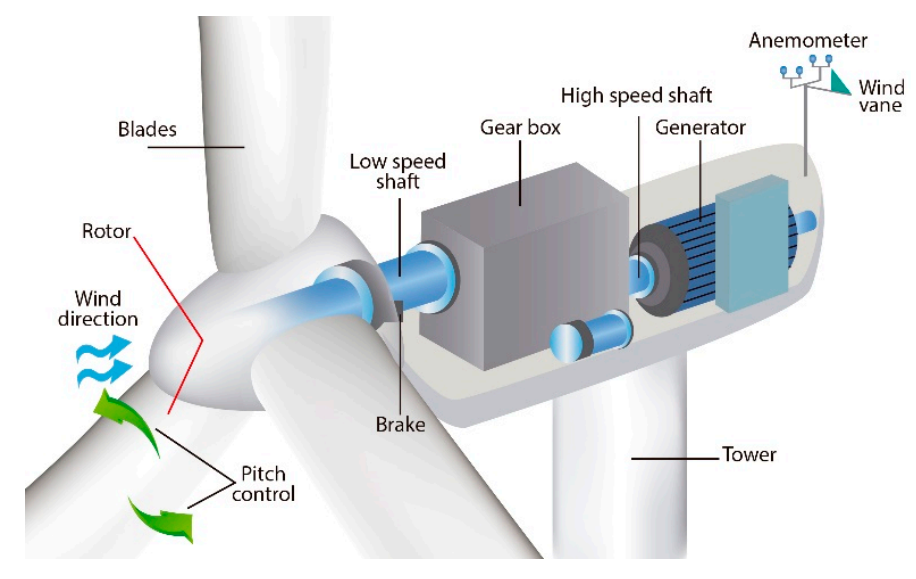

Figure 1. Parts of a wind turbine. 
To obtain the mathematical model of the wind power extracted by the rotor, an analysis of the wind passing between the blades in the swept area is made. The power extracted by the rotor is described with the following equation $[19,20]$ :

$$
P_{\text {rotor }}=\frac{1}{2} \rho A V^{3} C p
$$

where the wind density is $\rho$, the sweeping area is $A$, wind before the turbine is $\mathrm{V}$ and $\mathrm{Cp}$ is a power coefficient. To obtain the value of $C p$, an experimental method can be used, dependent of $\lambda$, pitch angle of the blade $\beta$ and $\alpha$ constant $[20,21]$. The value of $\alpha$ is obtained of Table 1 . The curve fit is a good approximation for values of $3<\lambda<15$, which are suitable for all blade configurations and models.

$$
\begin{gathered}
C p=\left(\sum_{i=0}^{4} \sum_{j=0}^{4} \alpha_{i, j} \beta^{j} \lambda^{i}\right) \\
\lambda=\frac{w_{r} R}{V}=\frac{2 \pi n R}{60 \mathrm{~V}}
\end{gathered}
$$

where $\mathrm{w}_{\mathrm{r}}$ is the rotation frequency $(\mathrm{rad} / \mathrm{s}), \mathrm{n}$ is the speed of rotation $(\mathrm{rpm})$ and $\mathrm{R}$ is the radius of the rotor $(\mathrm{m})$.

Table 1. Cp coefficients $\alpha_{i, j}$ [21].

\begin{tabular}{cccccc}
\hline $\mathbf{i}$ & $\mathbf{j}$ & $\boldsymbol{\alpha}_{\mathbf{i}, \mathbf{j}}$ & $\mathbf{i}$ & $\mathbf{j}$ & $\boldsymbol{\alpha}_{\mathbf{i}, \mathbf{j}}$ \\
\hline 4 & 4 & $4.9686 \times 10^{-10}$ & 4 & 3 & $-7.1535 \times 10^{-8}$ \\
4 & 2 & $1.6167 \times 10^{-6}$ & 4 & 1 & $-9.4839 \times 10^{-6}$ \\
4 & 0 & $1.4787 \times 10^{-5}$ & 3 & 4 & $-8.9194 \times 10^{-8}$ \\
3 & 3 & $5.9924 \times 10^{-6}$ & 3 & 2 & $-1.0479 \times 10^{-4}$ \\
3 & 1 & $5.7051 \times 10^{-4}$ & 3 & 0 & $-8.6018 \times 10^{-4}$ \\
2 & 4 & $2.7937 \times 10^{-6}$ & 2 & 3 & $-1.4855 \times 10^{-4}$ \\
2 & 2 & $2.1495 \times 10^{-3}$ & 2 & 1 & $-1.0996 \times 10^{-2}$ \\
2 & 0 & $1.5727 \times 10^{-2}$ & - & - & - \\
1 & 4 & $-2.3895 \times 10^{-5}$ & 1 & 3 & $1.0683 \times 10^{-3}$ \\
1 & 2 & $-1.3365 \times 10^{-4}$ & 1 & 1 & $6.0405 \times 10^{-2}$ \\
1 & 0 & $-6.7606 \times 10^{-2}$ & 0 & 4 & $1.1524 \times 10^{-5}$ \\
0 & 3 & $-1.3365 \times 10^{-4}$ & 0 & 2 & $-1.2406 \times 10^{-2}$ \\
0 & 1 & $2.1808 \times 10^{-1}$ & 0 & 0 & $-4.1909 \times 10^{-1}$ \\
\hline
\end{tabular}

The mechanical system can be modeled as a two-mass system without losing precision, which is shown in Figure 2.

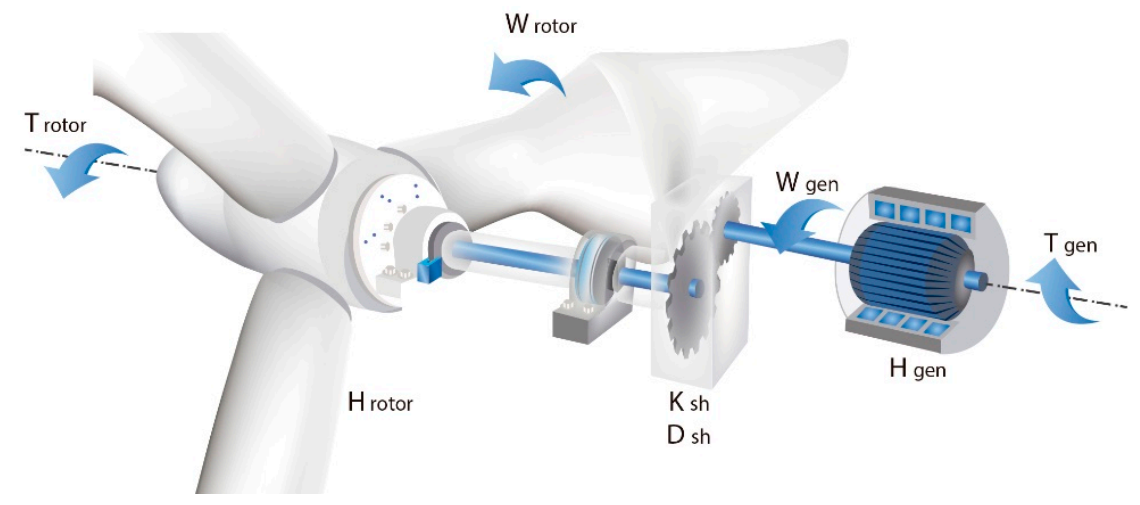

Figure 2. Two masses model for wind turbine. 
In the mathematical model, the torque of the rotor and the electromechanical torque of the generator act in opposition and are the inputs to the model, the rotation speeds are the output. The mathematical model is represented by the following equations [22,23]:

$$
\begin{gathered}
\frac{d w_{\text {gen }}}{d t}=\frac{1}{2 H_{\text {gen }}}\left[-\frac{P_{\text {elec }}}{w_{\text {gen }}+w_{0}}-D_{t g}\left(w_{\text {gen }}-w_{\text {rot }}\right)-k_{t g} \Delta \theta_{m}\right] \\
\frac{d w_{\text {rot }}}{d t}=\frac{1}{2 H_{\text {rot }}}\left[-\frac{P_{\text {mech }}}{w_{\text {rot }}+w_{0}}+D_{t g}\left(w_{\text {gen }}-w_{\text {rot }}\right)+k_{t g} \Delta \theta_{m}\right] \\
\frac{d\left(\Delta \theta_{m}\right)}{d t}=w_{\text {base }}\left(w_{g}-w_{t}\right)
\end{gathered}
$$

where the inertial constant depends on the geometrical distribution of the mass. Inertia represents the time in which the generator reaches its rated power with the kinetic energy of its mass in rotation [24]. Inertial moment is calculated according to:

$$
H_{\text {rotor }}=\frac{J_{\text {rotor }} w_{\text {rotor }}^{2}}{2 P_{n}} \quad \text { ó } \quad H_{\text {gen }}=\frac{J_{\text {gen }} w_{\text {gen }}^{2}}{2 P_{n}}
$$

In the case of the wind rotor, the inertia can be approximated according to:

$$
J_{\text {rotor }}=\frac{1}{8} m_{r} R^{2}
$$

where $\mathrm{m}_{\mathrm{r}}$ represents the mass of the rotor (includes the blades) and $\mathrm{R}$ is the radius of the rotor.

For the electrical modeling of a PMSG, the three phases are transformed into an equivalent of two axes. This is because each one acts in a defined geometric space of the air gap. With the direct axis (d) in phase with the winding of the rotor field and the quadratic or displacement axis (q), 90 electrical degrees forward in a synchronous rotating $d$-q reference frame. Magnetic flux waves due to the winding of the stator are presented in two sinusoidal waves distributed rotating with synchronous speed, such that one is the maximum point on the axis $d$ and the other is the maximum point on the axis $q$ [25]. The stator output voltages $\mathrm{d}-\mathrm{q}$ of this generator are given respectively by:

$$
\begin{gathered}
V_{d}=R_{d} I+L_{d} \frac{d I_{d}}{d t}-\omega_{g e n} L_{q} I_{q} \\
V_{q}=R_{q} I_{q}+L_{q} \frac{d I_{q}}{d t}+\omega_{g e n}\left(L_{d} I_{d}+\varphi_{f}\right)
\end{gathered}
$$

where $L$ are the inductances of the generator, $R$ is the resistance and $I$ is the currents in the axes $d$ and $q$ respectively. $\varphi_{f}$ is the permanent magnetic flux. $\omega_{g e n}$ is the rotation speed of the PMSG.

$$
\omega_{\text {gen }}=P_{p} \omega_{r e f}
$$

$P p$ is the number of pair of poles. Electromechanical torque $T_{g e n}$ can be express as:

$$
T_{\text {gen }}=\frac{3}{2} P_{p} \omega_{r e f}\left(\left(L_{q}-L_{d}\right) i_{d} i_{q}+\varphi_{f} i_{q}\right)
$$

\section{Expert Systems}

An Expert System (ES) is a computer program that imitates the reasoning of human beings, in other words, it is transferring the experience of a human to a computer through various formalities so that the computer executes the best solution. An ES is a flexible medium that proposes solutions to problems that cannot be tackled with traditional methods. Unlike a method that uses mathematical algorithms, ES efficiently searches for a solution within a solution space, uses acquired knowledge to 
abort non-promising spaces, and focuses on useful data. For the development of ES, three main theories are used: Fuzzy Logic (FL), Artificial Neural Network (ANN) and Intelligent Search Algorithms (ISA) [26].

\subsection{Fuzzy Logic}

FL is based on set theory to interpret linguistic knowledge in control rules, therefore a fuzzy logic controller (FLC) works without a mathematical model so it does not consider uncertainties and unknown parameters that make a non-linear system [27]. The development of an FL follows three steps [28-30]:

(1) Fuzzification: Translate the entries into a diffuse language using linguistic terms and functions of membership (MF), by virtue of the intuition, deduction, classification and reasoning of the human.

(2) Fuzzy rules: rules proposed by the expert technician in the system, which are described using simple words in natural language, usually two techniques are used to describe these rules:

Mamdani Inference Model:

$$
\text { IF } X_{1}=A_{1} \text { and } X_{2}=A_{2} \text { THEN } Y=B
$$

Takagi Sugeno Kang:

$$
\text { IF } \mathrm{X}_{1}=\mathrm{A}_{1} \text { and } \mathrm{X}_{2}=\mathrm{A}_{2} \text { THEN } \mathrm{Y}=\mathrm{F}\left(\mathrm{X}_{1}, \mathrm{X}_{2}\right)
$$

(3) Defuzzification: Conversion of the fuzzy set into a real value, by means of a mathematical method, to determine the control action. The most used mathematical methods are Centroid of Area, Bisector, Media of Maximum, and Center of Sums.

\subsection{Artificial Neural Networks}

ANN are computational models capable of analyzing, in detail, the behavior patterns of a large amount of data for each variable of the system, since they are made up of processing units inspired by the human brain (artificial neurons). The neurons are interconnected in layers, as shown in Figure 3. Each layer has different neurons that operate in parallel, the neurons are connected to the neurons of other layers and each connection has an associated weight (artificial synapses) that modulates the effect of the signs [31]. Each neuron $j$ with $n$ inputs $X$ has a value called activation state $\theta$ and an output function $F$ that provides the output signal $Y$. The output signal is sent to another neuron but its value can be modified according to the associated weight $\mathrm{w}$ [26]. Neurons can be represented as in Figure 4 .

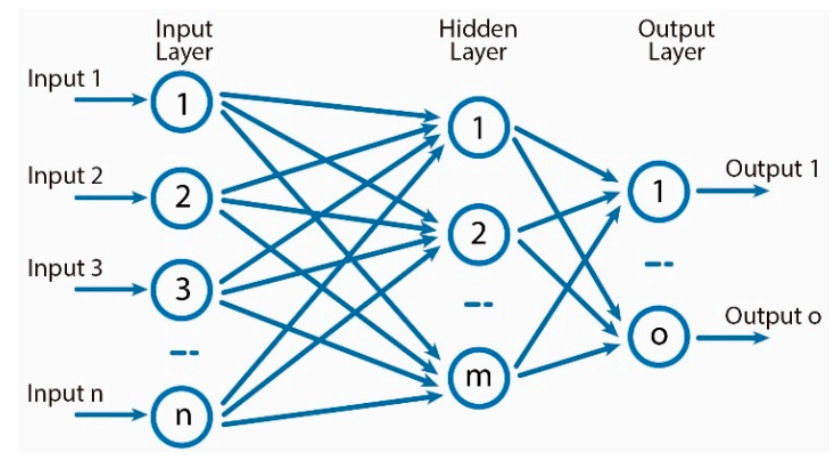

Figure 3. Architecture of a multi-layer neural network. 


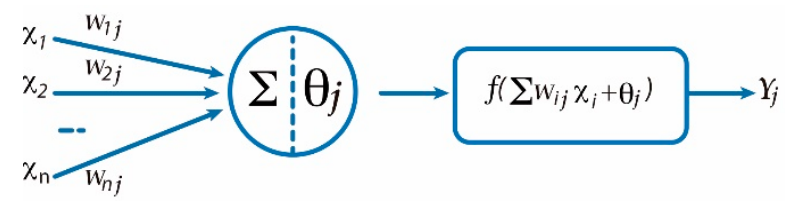

Figure 4. Artificial neuron model.

The learning of an ANN is based on the adjustment of the weights according to an optimization algorithm so that the network generates the best possible solution to a control system [32]. Different types of ANN can be distinguished according to their topology, training method, type of input-output data and the presentation of information. For example: multilayer perceptron (MLP); Neural network of radial base function (RBFNN); Reverse propagation networks (BPNN); Wavelet Neural Network (Wavelet NN); self-organized map NN (SOMNN); Recurrent Neural Network (RNN); NN time delay; Red Hopfield; NN self-associative; convolutional NN; learning of vector quantification networks; adaptive resonance theory (ART) NN; neuro-diffuse networks; Dynamic NN, among others [33].

\subsection{Intelligent Search Algorithms}

ISA are a method of search and information exchange between individuals in a population and are useful for solving complex and non-linear problems. Classical ISAs include Genetic Algorithms (GA), Particle Swarm Optimization (PSO) and Differential Evolution (DE); they are useful for solving optimization problems [26].

GA is an optimization method according to Darwinian principles of biological evolution: reproduction and survival of the fittest. According to [34], the algorithm consists of four steps, which are shown in Figure 5. The evolutionary process begins with a population of randomized solutions manually initialized. With the crossing between two solutions, the genetic information of two individuals is merged, generating better solutions. In the mutation new random solutions are generated, the best solutions are selected for the next generation. In the replacement, the previous generation of solutions is eliminated and the new generation is created with the best solutions of the crossing and the mutation. In each cycle, the termination condition of the algorithm is examined, by number of cycles, or by the minimum satisfactory error.

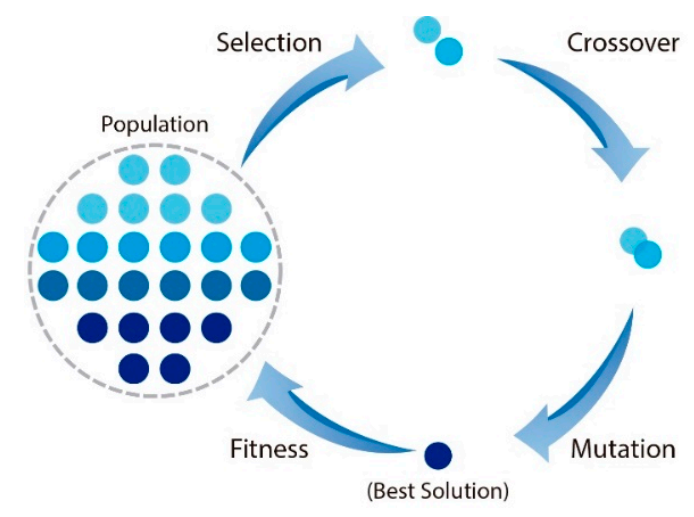

Figure 5. Cycle of the genetic algorithm.

A PSO are techniques that analyze behavior in their adaptation of different populations in nature, such as flocks of birds, whale banks, ant colonies and swarms of bees, to be imitated as a process of optimization using mathematical algorithms [26].

First a random population is generated, each member has velocity and position values around a solution space, in each step of the procedure, each solution is conducted to a weighted average and the best overall solution is updated. Thus, the solution space is reduced until an optimal solution is 
found [34]. The parameters that are adjusted so as not to exceed the processing resources are the size of the population and the detention criteria [35].

$\mathrm{DE}$ is a method that iteratively optimizes a solution with respect to a reference; the algorithm is based on the difference between the best solutions. Crosses and mutations can maintain the best solutions, discard deficient solutions and converge towards the optimal solution [26]. An ED converges faster because it uses few parameters when using differential mutation [27].

\section{Results: MPPT Techniques Review}

This work gathers a selection of scientific articles, dedicated to the elaboration of control systems with ES for MPPT in wind turbines with PMSG. For the elaboration of this analysis, about 100 scientific articles of different journals were considered. The most novel works were selected and with at least 4 years old. The selected articles are divided according to the methodology used, starting with FL, ANN and finally GA. As a result, a review of the work carried out is presented and a table with the results obtained by different authors for each used methodology is presented, besides, the most interesting schemes of control models are presented. The development of FLCs begin with simple control loop with two inputs, a variable and its error value, and one output signal as show in Figure 6. Different authors $[8,36-39]$ use as inputs the error between desired power and power measured in the generator $(\mathrm{eP})$, in addition to the difference of the error in certain time $\Delta(\mathrm{eP})$, these inputs are defined in (13) and (14).

$$
\begin{gathered}
e P=P_{g}(t)-P_{g, r a t e d}(t) \\
\Delta(e P)=e P(t)-e P(t-1)
\end{gathered}
$$

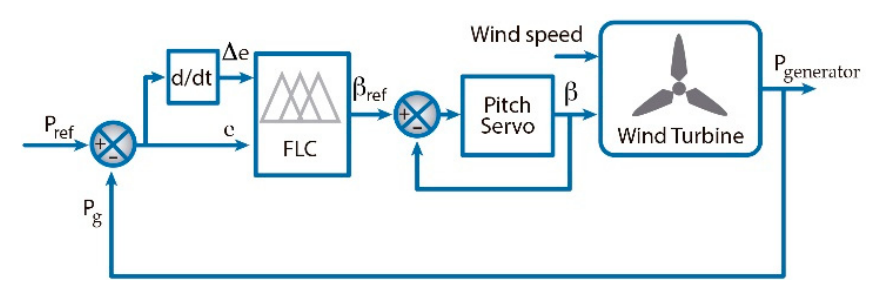

Figure 6. Basic scheme of fuzzy logic controller (FLC) for pitch angle [36-39].

With the same control logic, other authors [40-43] change the inputs variable and they use generator shaft speed error (ew) and the error difference $\Delta(\mathrm{e} \omega)$; and in $[44,45]$ they use torque error $(\mathrm{e} \tau)$ and the error difference $\Delta(\mathrm{e} \tau)$. In [46] combine types of variables; the Power error $(\mathrm{eP})$ and the generator shaft speed (ew) are used. In [47] is used one more input variable, the error power $(\mathrm{eP})$, variation of the power generated error $\Delta(\mathrm{eP})$ and generator shaft speed error $(\mathrm{e} \omega)$ are used.

Another group of researchers integrated proportional integral derivative (PID) control together with FLC to give greater stability to their control response. In [48] the author works with two PD controllers, torque control and pitch control and three FLC modules, FLC-1 to control the angle of the blade, FLC-2 for torque control and FLC-3 to control the speed of the rotor. All these controllers work in parallel to solve the wind problem higher than the nominal. This control model is shown in Figure 7. The control model used in [49] includes a proportional integral (PI) controller and an FLC. A correlation factor, defined by the error and the error derivative, assigns the weight that each controller will have, if the error is small, it will give more weight to the controller PI to maintain stability, if the error is large, it will give more weight to the FLC to obtain a faster control response. This control model is shown in Figure 8. In [50] a model similar to [49] is used, however the author adds a feed-forward FLC to adjust the angle of blade when there are gusts of wind. 


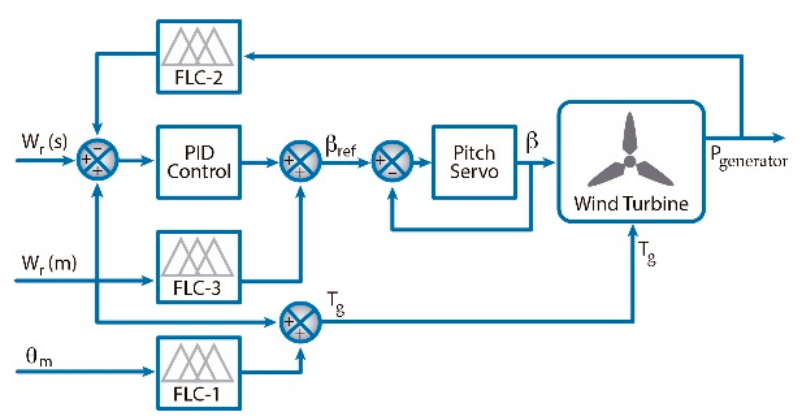

Figure 7. Control strategy with different control loops or different types of controllers, each control signal is added to obtain an equivalent signal [48].

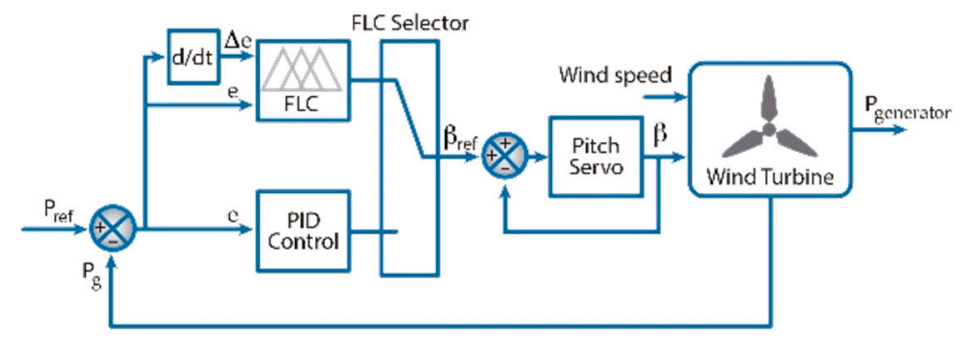

Figure 8. Different types of controllers where the control method is selected according to the needs of the system, the controller selection depends on a different controller [49].

In [51], the operating range of the turbine is divided into 5 sections according to the wind speed. In each section, a PID was implemented and the optimal gains were calculated previously. A FLC is used to switch between controllers. In the Figure 9, is shown this control strategy. However, in [52], an FLC is used to change the PID gains, according to the value of the error of the controlled variable, the gains are calculated previously.

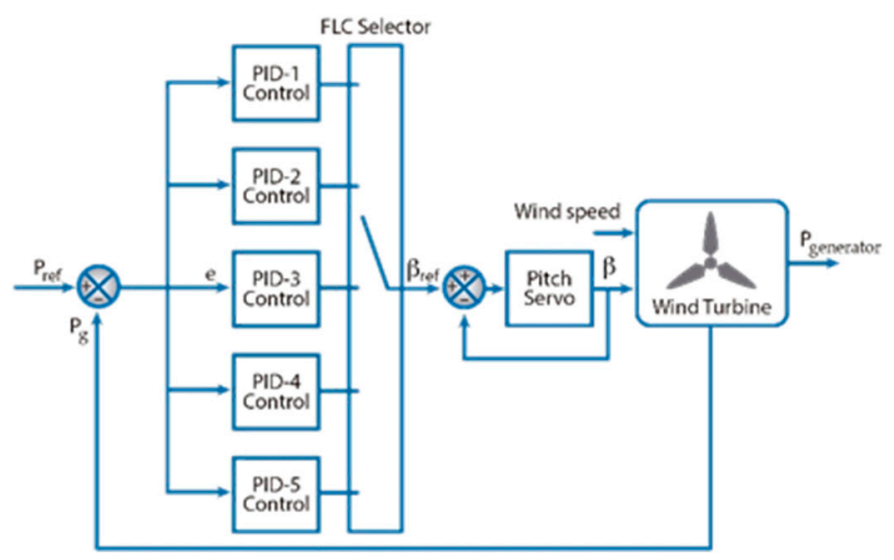

Figure 9. Selection of different proportional integral derivative (PID) controllers to obtain a steady state response in different operating ranges of the system [51].

The authors of [53] proposed a Fuzzy adaptive PID, where an FLC is used to calculate the gains for a PID control. In [54], an adaptive PI control is proposed, where the gains of the PI controller are set, but the generator power is used as the control variable. An example of these control strategies is shown in Figure 10. In [55], a feed-forward FLC is integrated to accelerate the response of pitch control when there are increases in the wind speed change and then added to the output value of FLC-PID controller. 


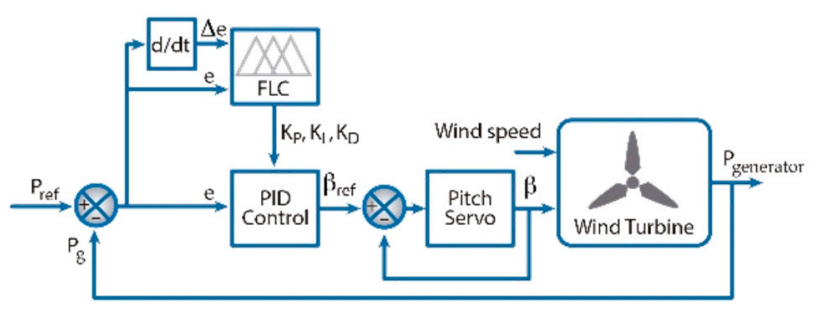

Figure 10. Adaptive control algorithm calculates the gains of a PID controller in real time; the strategy to change the values of the gains is done with FLC [52-54].

On the other hand, controllers of the hierarchical type have been proposed. In [56] two controllers are proposed, the first one is a classic fractional order PI (FOPI) controller, this controller implements an FLC to change the real-time PI gains (FFOPI). The second is a PI, the integral part is FFOPI and is added to the proportional part represented by a gain Kp (FFOPI + I). A PSO algorithm determined initial gains. In [57], the author proposes a control model (PIFPI) based on the combination of PI-Fuzzy-PI controllers to control the angle of incidence of the blades in a wind turbine. The error of the generated power is used as control variable, which is multiplied by the gains of a first PI (or PD), the value obtained is the input to an FLC that calculates the integration constant of the second PI controller. PIFPI controller is presented in Figure 11. In [58], a PID controller is presented, the values of proportional gain Kp and derivative $\mathrm{Kd}$ are the input for an FLC with an artificial organic controller (AOC) as the law of inference. The integration of the FLC output value represents Ki. The sum of the three constants is considered to be a controller (PID-AOC).

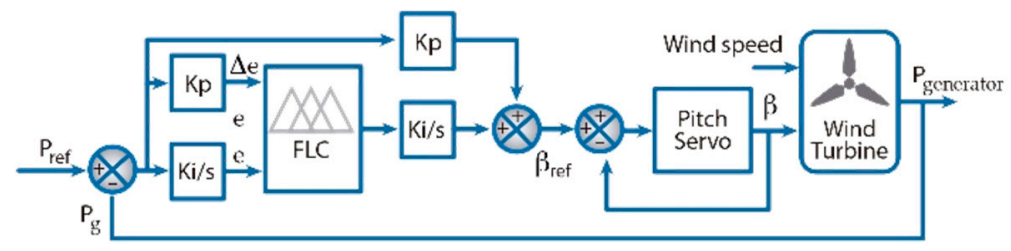

Figure 11. Controllers of the hierarchical type, PI-Fuzzy-PI [57].

In [59], an FLC is introduced that functions as a $\mathrm{P} \& \mathrm{O}$ controller. A P\&O disturbs the control variable in small samples and observes the resulting changes. A large sample can quickly reach the desired solution, but can generate oscillation around the optimal solution. A small sample can reduce the disturbance near the optimal solution, but it would arrive at this solution slowly when the wind speed changes abruptly. An FLC is added that adjusts the size of the sample dynamically, according to the changes in wind speed.

Different researchers have developed MPPT algorithms for pitch control for each blade. The authors of [60-62] propose using three FLC. One FLC controls the rotor torque by means collective pitch angle and, other two FLC control to blade moment. To adjust the blade pitch angles $\beta 1$, $\beta 2$ and $\beta 3$, the individual blade pitch make activity within a certain range to achieve the purpose of fatigue load reduction. One of the proposed individual pitch controllers is presented in Figure 12.

For the MPPT on the generator side [63], a control strategy with a FLC and an integral sliding mode current controller was implemented. FLC deduces the optimal current directly from the variations of current and voltage with good precision, it works as a harmonic compensator to eliminate voltage harmonics on the generator side. In $[64,65]$, vector control of the generator torque is performed by applying FLC.

Table 2 contains a summary of the works of different authors who implemented an FLC in wind turbines and who present numerical results of their research. 
Table 2. Summary of works done with FLC algorithms.

\begin{tabular}{|c|c|}
\hline Reference & Analysis of Results \\
\hline Tiwari et al., 2018 & $\begin{array}{l}\text { With a PI controller, the average power is } 16.9 \mathrm{~kW} \text { and generator speed varies. With } \\
\text { FLC the average power is } 17.2 \mathrm{~kW} \text { and the generator speed established at } 14.2 \mathrm{rad} / \mathrm{s} \text {. }\end{array}$ \\
\hline Barburajan, 2018 & $\begin{array}{l}\text { Was compared the responses of the Fuzzy-PID and PID controllers. F-PID reduces } \\
\text { rise time of } 4.21 \mathrm{~s} \text { to } 0.63 \mathrm{~s} \text {. PID has oscillations with a peak overshoot of } 11.8 \% \text { and } \\
\text { F-PID of } 0.02 \% \text {. }\end{array}$ \\
\hline Elyaalaoui et al., 2018 & $\begin{array}{l}\text { Comparing PI, PDFPI and PIFPI controllers, the maximum settling time is } 4 \mathrm{~s}, 4.7 \mathrm{~s} \\
\text { and } 2 \mathrm{~s} \text { respectively. The deviation (HZ) are }-0.06 \text { for IC, }-0.04 \text { for PI, }-0.045 \text { for } \\
\text { PDFPI, and }-0.01 \text { for PIFPI. }\end{array}$ \\
\hline Ponce et al., 2017 & $\begin{array}{l}\text { Pitch angle is smaller with PID-AOC }\left(5.2^{\circ}\right) \text { than with PID controller }\left(8.2^{\circ}\right) \text {. Stator and } \\
\text { rotor power increase significantly, } 10.8 \text { and } 30.5 \% \text {, respectively. PID generates } 2.5 \% \text { of } \\
\text { overshooting, while PID-AOC reaches } 0.8 \% \text {, increasing the performance in } 68.0 \% \text {. }\end{array}$ \\
\hline Alarcaon et al., 2017 & $\begin{array}{l}\text { According to error criteria compared between PID, diffuse and Hybrid (F-PID-5) } \\
\text { controllers. The F-PID- } 5 \text { obtained a minor error in the reference change. } 66.16 \% \text { better } \\
\text { than FLC basic controller and } 2.4 \% \text { with respect to a PID. }\end{array}$ \\
\hline Huang et al., 2017 & $\begin{array}{l}\text { Results show that generator speed response improves from } 3.68 \mathrm{~s} \text { to } 3.28 \mathrm{~s} \text { on } \\
\text { proposed method. Performance is improved in the attenuate oscillations of the } \\
\text { actuator and the overshoot of the generator speed has been reduced. }\end{array}$ \\
\hline Slimen et al., 2017 & Graphic results demonstrated better performance for FLC schemes than a PI control. \\
\hline Al-Toma et al., 2017 & FLC reduces the overshoot by about $10 \%$ compared with a PI controller. \\
\hline Aicha et al., 2017 & $\begin{array}{l}\text { The adaptive FLC-PI controller shows a good performance and delivers more } \\
\text { tracking speed and efficient maximum power tracking under fluctuating wind } \\
\text { conditions than PI and fuzzy-PI controllers. }\end{array}$ \\
\hline Cholo et al., 2017 & $\begin{array}{l}\text { A ripple percentage of } 2.13 \% \text { was obtained, } 84.28 \% \text { lower than that of a } \mathrm{P} \& \mathrm{O} \\
\text { controller, allowing to affirm that the FLC controller has a better result. }\end{array}$ \\
\hline Habibi et al., 2016 & $\begin{array}{l}\text { It was compared with a proposed PI with better response time of } 130 \mathrm{~s} \text { versus } 400 \mathrm{~s} \text {. } \\
\text { Overshoot reduction } 1 \% \text {. }\end{array}$ \\
\hline Pachauri et al., 2016 & $\begin{array}{l}\text { It compared with a PI controller. The settling time are Pitch angle } 0.9 \mathrm{~s} \text { for PI and } 0.3 \\
\text { for FLC. Torque } 1.0 \mathrm{~s} \text { for PI and } 0.25 \mathrm{~s} \text { for FLC. Rotor speed } 0.95 \mathrm{~s} \text { for PI and } 0.43 \mathrm{~s} \text { for } \\
\text { FLC. And EM torque } 0.9 \mathrm{~s} \text { for PI and } 0.3 \mathrm{~s} \text { for FLC. }\end{array}$ \\
\hline Smida and Sakly, 2016 & $\begin{array}{l}\text { It was compared with a PI control obtaining a better average error of } 0.018 \% \text { to } \\
0.0088 \% \text {, in absolute values it was reduced from } 65.8 \% \text { to } 29.02 \%\end{array}$ \\
\hline Beddar et al., 2016 & $\begin{array}{l}\text { The results illustrate the robustness and the superiority of FFOPI+I over FOPI and } \\
\text { conventional PI, since guarantee low current total harmonic distortion with small } \\
\text { overshot and fast settling time. }\end{array}$ \\
\hline Civelek et al., 2015 & $\begin{array}{l}\text { A PI reached best response time, an error in } 1 \% \text { in } 1.5 \text {, FLC } 3.5 \mathrm{~s} \text { and FLC-PID in } 0.35 \\
\text { s. Maximum Overshoot of the output power was reached to } 790 \mathrm{~kW}-\mathrm{PI}, 740 \mathrm{~kW}-\mathrm{FLC} \\
\text { and } 530 \mathrm{~kW}-\text { FLC-PID. }\end{array}$ \\
\hline Vega et al., 2015 & $\begin{array}{l}\text { The proposed combined controller FLC-PI has a better response than the PI controller } \\
\text { and the FLC, this has been proved with a lower error of } 0.4 \% \text { compared to } 0.66 \% \text { from } \\
\text { the PI and } 1.33 \% \text { from the FLC. }\end{array}$ \\
\hline Xiao et al., 2015 & $\begin{array}{l}\text { According to simulations, the proposed controller provides better performance } \\
\text { compared to a PID. Its behavior is better near the nominal wind speed reducing the } \\
\text { power overshoot to } 3 \% \text { than the cut-speed with only } 0.4 \% \text {. }\end{array}$ \\
\hline Yang et al., 2015 & $\begin{array}{l}\text { The average power for a conventional controller and the proposed is } 2.98 \mathrm{MW} \text { and } \\
3.01 \mathrm{MW} \text {, respectively. The speed rotor reached by gross controller is } 19.7 \mathrm{rpm} \text {, higher } \\
\text { than speed cut. Proposed controller reaches } 19.15 \mathrm{rpm} \text {, lower than speed cut. }\end{array}$ \\
\hline Van et al., 2015 & $\begin{array}{l}\text { The average output power simulate in } 2 \text { MW PMSG with the proposed methods is } \\
2.36 \%, 1.07 \% \text { y } 1.5 \% \text { respectively higher. }\end{array}$ \\
\hline
\end{tabular}




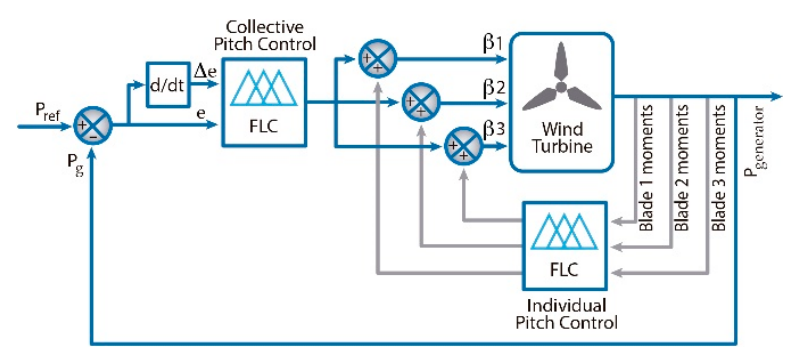

Figure 12. Control model that involves a combination of individual pitch control for each blade, this reduces the aerodynamic loads in the structure so it offers higher performance, and a collective pitch control to control the rotation of the turbine [61].

The control systems based on ANN have been used in wind energy; these systems work in any scenario, since they can adapt to the mode of operation in specific wind conditions. In [66] an adaptive integral sliding mode controller is proposed to obtain the optimum rotation speed of the rotor by means of an ANN. An RNN is used for online learning. The integral sliding mode control is designed to calculate the control voltage $\mathrm{u}_{\mathrm{q}}$ and the control voltage $\mathrm{u}_{\mathrm{d}}$, the value of these tensions are sent to a PWM controller that controls the power converter of the generator. This work is compared with a RBFNN used in [67]. The RBFN is used to determine the optimal current that controls the PMSG. The RBFN parameters are optimized using a PSO-modified algorithm to improve learning.

In [68], an algorithm is proposed that adapts the Bat Algorithm and improved Extreme Learning Machine (BA-ELM) for forecasting wind speed to alleviate the slow response of anemometers and sensors and eliminate the discontinuity of wind speed sequence, considering that the change of wind speed requires a very short response time. A state feedback control is proposed to achieve the rotor flux and rotor speed tracking. This method could decouple the current and voltage of induction generator to track the reference of stator current and flux linkage. This novel control strategy is shown in Figure 13.

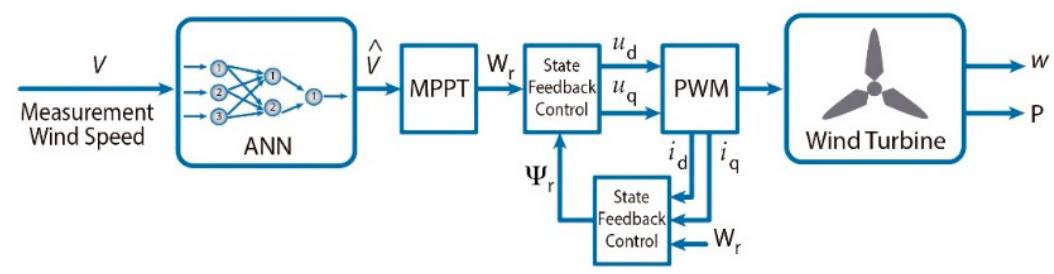

Figure 13. Control strategy where an Artificial Neural Network (ANN) is used to estimate the wind speed and thus buffer the discontinuity and slow response of an anemometer [68].

In [69], a method of pitch control is proposed, an ANN with an Online Learning Approach (OLA) is used. As an input variable, we have the error of the control variable; the error is previously filtered to transform a complex system into a simple one. In addition, a large sample observer is implemented to determine the rotor acceleration estimation, which avoids the use of additional sensors. The method must guarantee the monitoring of the rotor speed, the power of the generator and the limit value of the system variables.

In [70], an ANN topology based on RBFNN is proposed for learning from wind speed. To achieve maximum power generation, the system is implemented with a quadratic reinforcement converter and the inverter efficiency is validated with a primary and single-ended primary inductance converter (SEPIC). In [71], an ANN based on RBFNN is used. The controller uses the wind speed, generator speed and power generated as input variables. The work cycle and the angle of the blade are considered as the controlled variables. The selection of the output variable is based on the wind speed. In region II, the duty cycle is used to control the power electronics converter, thus obtaining the maximum available power. In region III, the pitch control is performed to limit the output power. A block diagram of this strategy is presented in Figure 14. 


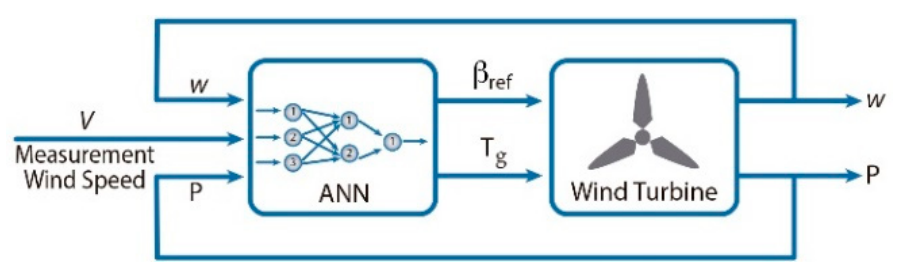

Figure 14. Block diagram of an ANN controller that selects the control signal according to the measured wind speed [71].

In [72], a Multy Layer Perceptron Neural Network (MLPNN)-based pitch angle controller and a non-linear speed controller based on Integral Sliding Mode Control (ISMC) are designed. MLPNN pitch controller limits the rotational speed when the wind speed exceeds its rated value; the weights connecting the neurons in different layers are trained by Back Propagation (BP) algorithm. ISMC adaptively changes the structure of the predefined controller according to the state of the system. Hence, the system response depends only on the sliding surface and is insensitive to variations of system parameters and external disturbances. The scheme of this control proposal is shown in Figure 15.

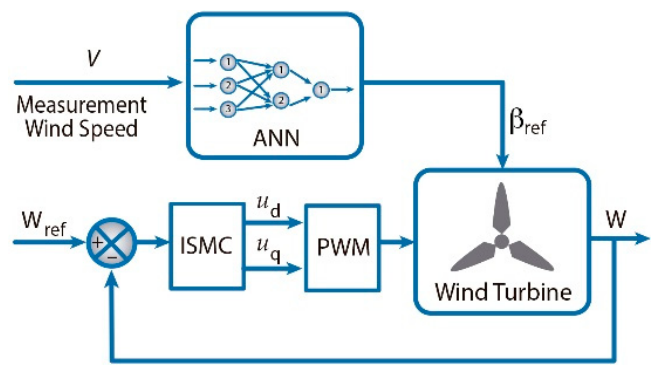

Figure 15. In the control strategy two techniques are used, Multy Layer Perceptron Neural Network (MLPNN) regulates the pitch angle and Integral Sliding Mode Control (ISMC) adjusts the rotor speed reference independently of external disturbances [72].

In [73], an adaptive controller based on RBFNN is suggested without previous adjustment and with updating of the weights in line. The Lyapunov functions are used to derive the update rules. For the pitch controller, two RBF networks solve the non-linear space state equation. In [74] an RBFNN is used with an input layer for the power supply error, a hidden layer with 25 neurons and an output layer with the approximate non-linear part. The training algorithm is a descending gradient. The result is greater stability in the extraction of wind energy. This control strategy is explained with Figure 16.



Figure 16. ANN control strategy, acts on the control pitch and the speed of the generator. Uses as input, the error in the generator speed and the power generated [74].

In [75], the author proposes an individual pitch controller based on RBFNN. The controller requires two inputs variables, the error in the speed of the rotor axis and the measurement of the wind speed by Light Detection and Range (LIDAR). Better performances are obtained than with a PI controller, but with wind speed disturbances, the controller does not work properly. This is because LIDAR measurements delay the controller and cannot anticipate wind speed. The design of this methodology is shown in Figure 17. The design of this methodology is shown with Figure 17. 


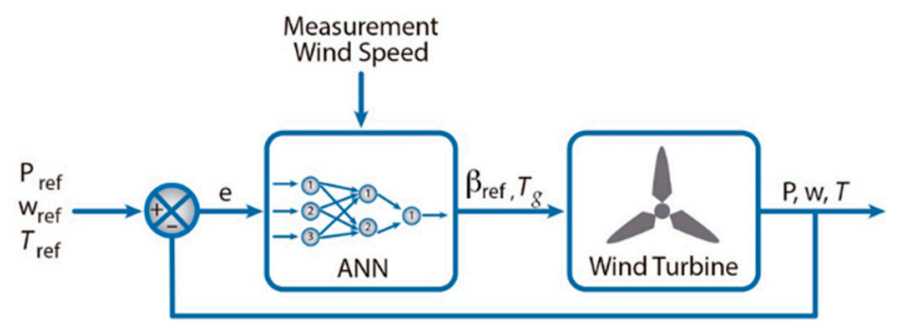

Figure 17. Individual pitch controller based on a neural network of radial base function (RBFNN) model, which measures wind speed with light detection and range (LIDAR) [75].

In [76], the author works with two adaptive neuro-fuzzy inference system (ANFIS), combining ANN with FLC decision process without requires sensor for wind speed. The first ANFIS for wind speed estimation uses generated power and rotor speed as inputs and the output is wind speed. The second ANFIS uses the wind speed estimation of first ANFIS as input to give the optimum rotor speed. In [77], an ANN based on reinforcement learning (RL) is proposed. RL process learns the optimal relationship between rotor speed and electric power. The algorithm changes online, the RL process to application process when it has the optimal relationship. The RL process can be reactivated online any time the actual optimal relationship deviates due to a change in the environment. The block diagram of this strategy is presented in Figure 18.

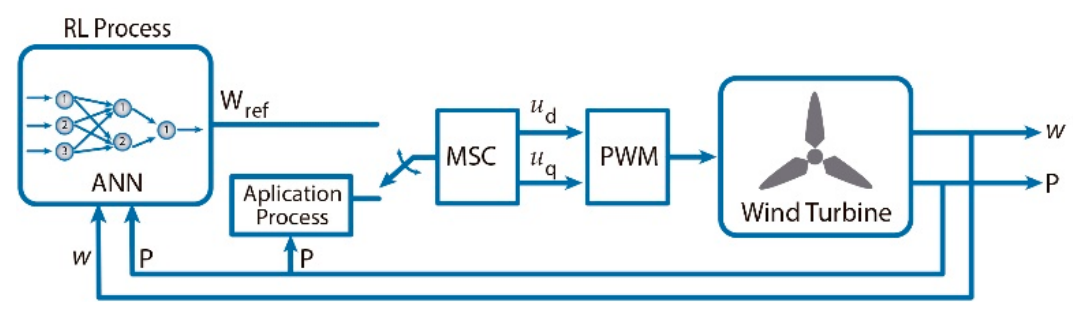

Figure 18. ANN trained by a reinforcement learning (RL) algorithm, the system changes to application mode and returns to learning mode when there are changes in the environment, until it is trained again [77].

In [78], a function of Nussbaum type is proposed to solve the non-linearity of the system and an RBFNN to determine the set-point values of the variable speed and variable angle controllers. The strategy is to control the generator torque before the rotor speed reaches the nominal speed. At the rated speed, the generator torque also reaches its nominal value and cannot be used as a control strategy, so the angle control of the blade is adopted as an input to maintain the rotor speed at its nominal value.

In [79], the author presents a pitch angle controller that is based on equaling $C p_{\text {ref }}=C p_{\text {opt }}$. If the wind speed is higher than nominal speed, $C p_{\text {opt }}$ must be a small value, so ANN calculates a high value of $\beta_{\text {ref }}$; and if the wind speed is lower than nominal speed, $C p_{\text {opt }}$ must be a higher value, so ANN calculates a low value of $\beta_{\text {ref. }}$. The training process is performed using the Levenberge-Marquardt algorithm to search for optimal synaptic weights. In [80], a control method is presented, based on an adaptive ANN-PID in which the PID parameters are regulated automatically. The gradient descent method is used to optimize ANN weights. This control strategy is shown in Figure 19.

In [81], a PI generator torque control is presented. In order to tune the PI gains, a RBFNN is used. The optimal dataset to train this neural network is provided by the Gravitational Search Algorithm (GSA). The block diagram of this strategy is presented in Figure 20.

In [82], is proposed a real-time wind speed estimation method and sensorless control for power generation. An extreme learning machine (ELM) realizes the wind speed estimation. A specific variable of wind turbine is used for improving its performance with considering the variable pitch angle. Since the design is independent of air density, the proposed ELM method for wind speed 
estimation is robust to temperature variations. The estimated wind speed is calculated to determine the optimal pitch angle.

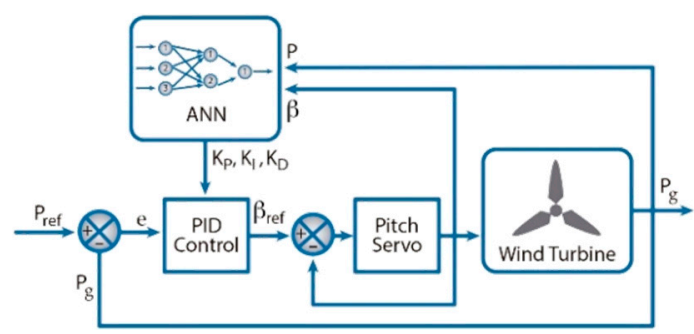

Figure 19. A PID controller is used to regulate the pitch angle and perform the MPPT; an ANN is used to adapt the PID gains in any state of the system [80].

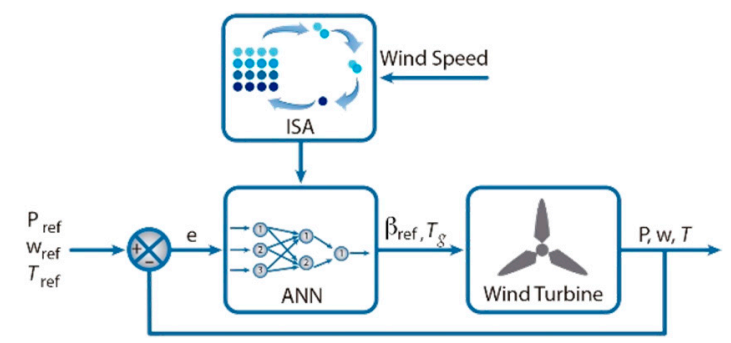

Figure 20. In control systems, ISO algorithms are used to train an ANN with greater speed, the purpose of the ANN is varied, and in this case, the reference of the pitch angle and generator torque is obtained [81].

Table 3 presents a summary with ANN algorithms for MPPT for wind energy.

ISA is a method that imitates natural evolutionary processes to optimize a solution to a complex problem. In the control of wind turbines, it has been commonly found as a search tool to obtain optimal control parameters applied to other types of controllers. In [83], the author uses a whale optimization algorithm (WOA) to find optimal parameters of conventional PI controllers. WOA-PI is applied to a machine-side converter to find the optimum PMSG voltages under normal conditions. The WOA simulates the pursuit behavior of humpback whales, where they try to surround the prey near the surface of the water by making a spiral-shaped web of bubbles around the bank of fish. Despite a change in wind speed, optimum dynamic performance of PMSG is achieved.

In [84], an Ant Colony Optimization (ACO) based algorithm is proposed. The ants initially walk randomly, and once they find food, they return to their colony leaving a trail of pheromones. If other ants find this trace, it is likely that they do not continue to walk randomly, they may follow the trail of pheromones, returning and reinforcing if they find food eventually. However, the pheromone trail evaporates, reducing its attractive force. The longer it takes an ant to travel the road and return, the longer pheromones have to evaporate. A short path, in comparison, is walked more frequently, so the density of pheromones becomes larger in short paths than in long ones. The ACO controller is responsible for the quick charge of the battery and then use the energy in the wind system. A converter is used to maximize the power stages.

In [85], a system for controlling Matrix Converter (MC) based on hysteresis current controller is proposed. A Bacterial Foraging Optimization BFO is employed for better PI parameters to choose proper idref so that the controlled system has fast response performance. PI controller is employed for controlling the active and reactive current components of the PMSG. The algorithm mimics the foraging behavior of Escherichia coli (E. coli) bacteria present in the human intestine. Artificial bacteria perform three basic foraging activities: chemotaxis where the bacteria move to nutrients, reproduction, for which the bacteria are divided into two surviving the strongest, and elimination-dispersion, where bacteria can be eliminated or forced to move to another place. This process increases the diversity of the solutions and improves the search for local maximums and minima. 
Table 3. Summary with ANN algorithms for MPPT for wind energy.

\begin{tabular}{|c|c|}
\hline Reference & Analysis of Results \\
\hline Yin and Zhang, 2019 & $\begin{array}{l}\text { Comparative experimental results with [67] demonstrates that the proposed } \\
\text { controller possesses a remarkable learning capability of the RNN weights and can } \\
\text { be used to maintain the optimum generator power. }\end{array}$ \\
\hline Zhang et al., 2019 & $\begin{array}{l}\text { Results show that the flux linkage and turbine rotational speed tracking the } \\
\text { reference value almost without oscillation and back to stable state, which indicates } \\
\text { its highly acceptable tracking performance, considering the quick reaction and } \\
\text { following-up time. }\end{array}$ \\
\hline Jiao et al., 2019 & $\begin{array}{l}\text { With turbulent wind the standard deviation of generator shaft speed is } 0.0206 \mathrm{rad} / \mathrm{s} \\
\text { for NN controller, and } 0.0351 \mathrm{rad} / \mathrm{s} \text { for the PI counterpart. The NN controller can } \\
\text { produce smaller oscillation and provide electrical energy with higher quality for } \\
\text { grid integration. }\end{array}$ \\
\hline Tiwari et al., 2018 & $\begin{array}{l}\text { The results are compared with a classical Perturb and Observe }(\mathrm{P} \& \mathrm{O}) \text { method. The } \\
\text { overall performance comparison of the maximum power drawn was } 7.28 \% \text { greater } \\
\text { using the Boost converter, } 3.68 \text { with the SEPIC converter and } 3.34 \text { with the } \\
\text { quadratic increase converter for wind speed below the rated speed. }\end{array}$ \\
\hline Tiwari et al., 2017 & $\begin{array}{l}\text { The proposed controller gives } 2.021 \%, 4.623 \% \text { and } 9.893 \% \text { more power during } \\
\text { below rated wind speed and during above rated wind speed it produces } 0.187 \% \text {, } \\
1.67 \%, 3.67 \% \text { and } 5.38 \% \text { of rated generator power than the BPN, FLC and PI } \\
\text { controller respectively. }\end{array}$ \\
\hline Heshmatian et al., 2017 & $\begin{array}{l}\text { A comparison is made between MLPNN controller and conventional PI regarding } \\
\text { their performance in adjusting the pitch angle. The results approve the designed } \\
\text { controller to be much faster and more accurate than the conventional PI. }\end{array}$ \\
\hline Roodsari et al., 2017 & $\begin{array}{l}\text { Compared with a well-designed PID controller the proposed adaptive controller } \\
\text { shows less fluctuation in following the desired system power pattern and less rotor } \\
\text { speed errors. }\end{array}$ \\
\hline Mjabber et al., 2017 & $\begin{array}{l}\text { Compared with a PI controller. Rotor speed is very stable and its fluctuation are } \\
\text { considerably reduced. The pitch angle variations are much lower. The generator } \\
\text { torque is very stable, the mean value is only } 133.5-\mathrm{kNm} \text { than the } 139.4 \mathrm{kNm} \text { given } \\
\text { by PI. }\end{array}$ \\
\hline Han et al., 2017 & $\begin{array}{l}\text { The baseline controller is compared with PI controller. The effectiveness of } \\
\text { controller is evaluated based on the damage equivalent loads. The tower base } \\
\text { fore-aft moment was reduced by } 15.3 \% \text {, the tower base side-to-side moment was } \\
\text { reduced by } 9.8 \% \text {, and the tower base torsional moment was reduced by } 10.4 \% \text {. }\end{array}$ \\
\hline Rahman et al., 2016 & $\begin{array}{l}\text { The performance ANFIS controller is compared with ANN controller. The } \\
\text { maximum power error is } 0.0095 \text { watts for ANN and } 0.000123 \text { watts for ANFIS. }\end{array}$ \\
\hline Wei et al., 2016 & $\begin{array}{l}\text { The proposed algorithm enables the PMSG to produce a total energy of about } 8.4 \mathrm{~kJ} \\
\text { in the two minutes, which is } 5 \% \text { more than } 8 \mathrm{~kJ} \text { energy produced by the PMSG with } \\
\text { a conventional P\&O method. }\end{array}$ \\
\hline Bagheri and Sun, 2016 & $\begin{array}{l}\text { The simulation results are analyzed alongside a PI controller and the controller } \\
\text { designed for Jafarnejadsani et al. (2013). The proposed controller can precisely track } \\
\text { the desired rotor speed in second region, but not the other controllers. The tracking } \\
\text { error of the proposed controller is lower resulting in a lower generator torque. }\end{array}$ \\
\hline Dahbi et al., 2016 & $\begin{array}{l}\text { Graphic results show good behavior on the optimal rotor speed. Increased } \\
\text { efficiency and performance of the turbine. The grid voltages and injected currents } \\
\text { are in phase; therefore, unit power factor is reached. }\end{array}$ \\
\hline Kang et al., 2014 & $\begin{array}{l}\text { It was compared between traditional PID, PID-NN though standard PSO and } \\
\text { adaptive PID-NN. Was documented the errors varied with time, with a time } \\
\text { interval of } 0.001 \mathrm{~s} \text {. The adaptive PID-NN controller has fast convergence speed, } \\
\text { high accuracy and stability. }\end{array}$ \\
\hline Wu et al., 2013 & $\begin{array}{l}\text { The proposed ELM wind speed estimation and sensorless control are proved } \\
\text { effective. In most of the time, the wind speed error is less than } 0.05 \mathrm{~m} / \mathrm{s} \text {. }\end{array}$ \\
\hline
\end{tabular}


In [86], a GA is suggested for the optimization of PID parameters. The algorithm determines the mutation rate, the crossing point and the number of iterations for an optimal solution. The criteria of validation of the objective function are the error of the controlled variable is within the minimum allowed and the generated energy is greater than the established value. In [87], a pitch controller based on the Moth-Flame Optimization algorithm (MFO) is proposed. MFO mimics the navigation sense of moths. The moths fly at night and maintain a fixed angle to the moon to travel in straight lines. This technique assumes that the candidate solutions are moths and that the moths fly in a three-dimensional space where each of the axes represent the control gains $\mathrm{Kp}, \mathrm{Ki}$ and $\mathrm{Kd}$.

In [88], a frequency regulation strategy is introduced for the PMSGs connected to the grid. The controller extracts the active power and regulates the discharge to the grid. In addition, it dampens the instability in the wind turbine due to the excessive discharge of kinetic energy (KE). A PSO optimization method is used that maximizes the KE reserves in the turbines for reference of the power discharged to the network.

In [89], the authors proposed controlling the work cycle in a Buck-boost converter through PSO, so that the wind power can be extracted to the maximum. The voltage and current values generated are the verifiable input that is used to determine the duty cycle and thus obtain an ideal generated power. With this controller, the wind turbine is more efficient at changes in wind speed, reducing losses in changes in speed of rotation.

In [90], the authors introduce a technique for optimally obtaining the gains of the proportional integral (PI) controllers. The technique is based on developing a space of states model and obtaining the eigenvalues of the matrix A of the state space model. These eigenvalues are utilized for determining the optimum values of the PI controller's gains in order to perform the optimal system operation using Linearized Biogeography-Based Optimization (LBBO) technique. LBBO deals with the migration of species and animals between their habitats. Every habitat in LBBO represents a possible solution. The Habitat Suitability Index (HSI) of each habitat is used for measuring the fitness of this solution. A high HSI is considered as a good solution. A suitability index variable (SIV) is a number of features related to any solution. The problem dimension is obtained using the number of SIVs in each solution. Two main operations have to be performed in BBO to obtain the offspring generation. The first operation is the migration strategy, which is the way of the recombination between the solutions. The second operation is the mutation process.

In [91,92], the authors use an Integral Proportional controller with gain $\mathrm{Kp}$ and $\mathrm{Ki}$ in the control loop of the tilt angle. However, the proportional gain $\mathrm{Kp}$ and the integral gain $\mathrm{Ki}$ are tuned through the PSO algorithm.

In [93], the author proposes a GA method that generates a set of diffuse IF-THEN rules for genetic operations such as: crossing, mutation, selection; and calculates the resulting solution. Through an ANN the generated rules are compared with the optimal values, the rules that satisfy most of the values are good rules. The algorithm replaces the worst fuzzy rules with the new fuzzy rules that generate better solutions. These rules establish the pitch angle in the best configuration to optimally control the wind turbine.

In [94], a gain search control (GSC) is used for a PID controller that regulates pitch angle. The algorithm uses a set of linear quadratic Gaussian operations to obtain a fast and accurate response at several operating points that represent a de-wind speed. An optimization algorithm changes the controller used according to the point of operation, so the controller suppresses the transient oscillations and achieves a good and fast stabilization.

In Figure 21, a general scheme of an ISA algorithm is shown. The majority of ISA control strategies are used as a search engine in the application of a control model, where the best values are obtained to perform a control strategy, usually a controller with a mathematical model such as a PID. Table 4 presents a summary of the results of each technological development carried out with ISA. 


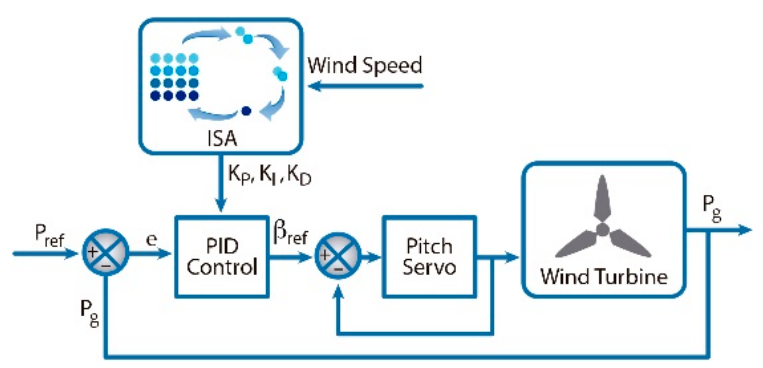

Figure 21. In control systems, ISO algorithms are used to search the best values to perform a control strategy, in this case to search the best gains values for a PID controller.

Table 4. Summary with Intelligent Search Algorithms (ISA) for MPPT for wind energy.

\begin{tabular}{|c|c|}
\hline Reference & Analysis of Results \\
\hline Mohamed et al., 2019 & $\begin{array}{l}\text { The results show that the dynamic responses for }\left(T, \omega, i_{d}, i_{q}\right) \text { by using WOA based } \\
\text { controller results have lower overshoot and smaller setting time than other methods. }\end{array}$ \\
\hline Priyadarshi et al., 2018 & $\begin{array}{l}\text { Experimental results reveal that the ACO based MPPT provides seven times faster } \\
\text { convergence compared to the PSO algorithm for achievement of MPP and } \\
\text { tracking efficiency. }\end{array}$ \\
\hline Saad et al., 2018 & $\begin{array}{l}\text { The proposed control method has a fast, dynamic response by controlling the } \\
\text { generator d-axis current to get the maximum active power under normal wind } \\
\text { velocities. In addition, the controller proves to have capability and fast transient } \\
\text { response under grid fault condition. }\end{array}$ \\
\hline Civelek et al., 2016 & $\begin{array}{l}\text { According to the results, an appreciable improvement of } 17 \% \text { was calculated on } \\
\text { power overshoot with intelligent GA respect to classic GA. Furthermore, stability } \\
\text { time was } 0.79 \text { better, with controller proposed. }\end{array}$ \\
\hline Ebrahim et al., 2018 & $\begin{array}{l}\text { According to simulations, the suggested design can guarantee system stability under } \\
\text { increased mechanical torque perturbations and excessive wind speed with controller } \\
\text { parameters uncertainties. Thus, the proposed approach succeeded in proving its } \\
\text { capability to select the most robust PID controller. }\end{array}$ \\
\hline Kim, 2017 & $\begin{array}{l}\text { The results demonstrate that the proposed strategy can restrict the frequency drop, } \\
\text { decrease the disturbances PMSG. }\end{array}$ \\
\hline Duad et al., 2016 & $\begin{array}{l}\text { With the PSO method, the system achieves a new speed of rotor and stabilized in less } \\
\text { than } 0.1 \mathrm{~s} \text {. The system also achieves new output power and is stabilized in less than } \\
0.2 \mathrm{~s} \text {. When compared with wind turbine system without MPPT, there has been an } \\
\text { increasing average efficiency of } 25 \% \text {. }\end{array}$ \\
\hline Yassini et al., 2016 & $\begin{array}{l}\text { Simulation and experimental results show that LBBO is a successful optimization } \\
\text { technique in control systems for wind turbine system. }\end{array}$ \\
\hline Behera et al., 2016 & $\begin{array}{l}\text { The standard deviation in angular speed of rotor is seen to be low with the proposed } \\
\text { PI-PSO controller }(0.0338 \mathrm{pu}) \text { as compared to the standard P control }(0.0384 \mathrm{pu}) \text { and } \\
\text { without control }(0.0482 \mathrm{pu}) \text {. Similarly, the pitch angle has increased less }\left(5.0911^{\circ}\right) \text { as } \\
\text { compared to } \mathrm{P} \text { control }\left(7.0107^{\circ}\right) \text {. }\end{array}$ \\
\hline Hodzic and Tai, 2015 & $\begin{array}{l}\text { The performance of the PI-PSO controller produces less oscillations in every analyzed } \\
\text { case, especially when wind speed is higher. However, the overshoots are bigger and } \\
\text { settling times are longer. }\end{array}$ \\
\hline Kasiri et al., 2015 & $\begin{array}{l}\text { Graphic results shown that in below rated wind speed, optimal power is attained by } \\
\text { regulating; thus, the pitch angle is kept at a mechanical minimum and rotor speed is } \\
\text { controlled in such a way that it is always acquired, akin to MPP tracking. }\end{array}$ \\
\hline
\end{tabular}

\section{Discussion and Conclusions}

After making an analysis of different expert control systems applied in MPPT of wind turbines, FLC, ANN and ISA are considered the most analyzed strategies. It has been shown that they are very useful control strategies to solve the problem of non-linearity of the system variables. 
Conventional control systems based on mathematical models such as PID controllers have proven to be very reliable with stable systems, but they present a slow response when it is required to respond to major perturbations of the system. This is because they can develop the adaptation in systems where it is not possible to have a mathematical model, organize the information for analysis and prediction of the response of the controller, as well as optimize the solution of a set of solutions imitating the patterns of biological behavior of the species. The main contribution of an ES simplifies the non-linearity of the variables of a system.

An FLC is based on brain functions such as language, processes information and formulates solutions according to programmed rules defined by the experience of human beings. An ANN bases its operation on the self-learning of its connection weights, so they predict changes in their input variables and as a result, has a faster response. An ISA uses characteristic behavioral patterns of nature to optimize the search for the appropriate solution.

The wind turbines of last generation, due to their high altitude, have faced intense gusts of wind that generate multiple oscillations, mechanical stress and risks for the system itself; these have, therefore, required a very precise driver for these operating conditions. The use of ES has contributed to give solutions to this problem, thanks to its adaptability to sudden changes since its control action does not depend on a mathematical model.

Because of this analysis, we obtained the assertion that a wind turbine system works in a stable state, when the winds are constant and in a transient state in the presence of gusts or turbulence. An MPPT controller must be efficient in both cases. The recurrent technique by diverse authors is the combination of a conventional PID controller with an expert controller. A conventional PID controller can obtain a high precision in stable state, and an expert system, to not consider the perturbations of the environment, has a faster response in transient state. For this purpose, it is more common to use the PID command with FLC, the controllers can work in parallel by adding their control signals or by selecting the type of response desired according to the state of the system. It is also convenient to use an expert FLC, ANN or ISA system to adjust the control gains of a PID to work stably in different wind speed ranges. Another option is the use of hierarchical systems, where several controllers are connected in cascade, the output of one is the input of the next, in this way different types of controllers can be combined, so that the final control signal is optimized. All these techniques are used both for a simultaneous operation of the blades, as for an individual pitch control.

The use of ANN in wind power systems has been very successful in predicting air velocity, which is very valuable in anticipating the control response. The most complete control proposals obtain the value of the angle of inclination using only values obtained directly from sensors. The ISAs are used to a greater extent for the learning of the weights in ANNs or for the efficient search of the optimal solution among a set of solutions. The combination of these systems is a factor of success in obtaining the maximum power of a wind turbine, since they have higher response time and efficiency.

Author Contributions: Review, methodology and Writing-Original Draft preparation, E.C.-N.; formal analysis and validation, R.V.C.-S.; discussion, data curation and Writing-Review and Editing, M.T.-P. and J.G.R.-M.; resources, supervision, project administration and funding acquisition, J.C.J.-C.

Funding: This research received no external funding.

Acknowledgments: This work was supported by Departamento de Investigación y Posgrado of the Facultad de Ingeniería and Universidad Autónoma de Querétaro.

Conflicts of Interest: Authors declare no conflict of interest.

\section{References}

1. Court, V. Energy capture, technological change, and economic growth: An evolutionary perspective. BioPhys. Econ. Resour. Qual. 2018, 3, 1-27. [CrossRef]

2. Sawyer, S.; Dyrholm, M. Global Wind Report Annual Market Update 2017; GWEC Global Wind Energy Council: Brussels, Belgium, 2018. 
3. Wang, L.; Liu, X.; Kolios, A. State of the art in the aeroelasticity of wind turbine blades: Aeroelastic modelling. Renew. Sustain. Energy Rev. 2016, 64, 195-210. [CrossRef]

4. González-González, A.; Jimenez-Cortadi, A.; Galar, D.; Ciani, L. Condition monitoring of wind turbine pitch controller: A maintenance approach. Measurement 2018, 123, 80-93. [CrossRef]

5. HMI Vestas Offshore Wind A/S, Dusager 4, 8200 Aarhus N, Denmark Aarhus. Available online: http: //www.mhivestasoffshore.com/mhi-vestas-launches-the-first-10-mw-wind-turbine-in-history (accessed on 25 September 2018).

6. Bibave, R.; Kulkarni, V. A novel maximum power point tracking method for wind energy conversion system: A review. In Proceedings of the International Conference on Computation of Power, Energy, Information and Communication (ICCPEIC), Chennai, India, 28-29 March 2018.

7. Novaes-Menezes, E.J.; Araújo, A.M.; da Silva, N.S.B. A review on wind turbine control and its associated methods. J. Clean. Prod. 2018, 174, 945-953. [CrossRef]

8. Slah, H.; Mehdi, D.; Lassaad, S. Advanced control of a PMSG wind turbine. Int. J. Mod. Nonlinear Theory Appl. 2016, 5, 1-10. [CrossRef]

9. Amulya, M.; Prashanth, C.; Vijaya, M. Controlling flicker caused due to power fluctuations by using individual pitch control for a variable speed DFIG based wind turbine. Int. Res. J. Eng. Technol. 2017, 4, 286-293.

10. Tiwari, R.; Babu, N.R. Recent developments of control strategies for wind energy conversion system. Renew. Sustain. Energy Rev. 2016, 66, 268-285. [CrossRef]

11. Soued, S.; Ebrahim, M.A.; Ramadan, H.S.; Becherif, M. Optimal blade pitch control for enhancing the dynamic performance of wind power plants via metaheuristic optimizers. IET Electr. Power Appl. 2017, 11, 1432-1440. [CrossRef]

12. Asghar, A.B.; Liu, X. Estimation of wind turbine power coefficient by adaptive neuro-fuzzy methodology. Neurocomputing 2017, 238, 227-233. [CrossRef]

13. Karthi, K.; Radhakrishnan, R.; Baskaran, J.; Sam-Titus, L. A review of maximum power point tracking controls and wind electric generators. In Proceedings of the International Conference on Inventive Research in Computing Applications (ICIRCA), Coimbatore, India, 11-12 July 2018.

14. Abdullah, M.A.; Yatim, A.H.M.; Tan, C.W.; Saidur, R. A review of maximum power point tracking algorithms for wind energy systems. Renew. Sustain. Energy Rev. 2012, 16, 3220-3227. [CrossRef]

15. Kumar, D.; Chatterjee, K. A review of conventional and advanced MPPT algorithms for wind energy systems. Renew. Sustain. Energy Rev. 2016, 1, 957-970. [CrossRef]

16. Amrouche, S.; Rekioua, D.; Rekioua, T.; Bacha, S. Overview of energy storage in renewable energy systems. Int. J. Hydrog. Energy 2016, 41, 20914-20927. [CrossRef]

17. Chavero-Navarrete, E.; Perea, M.T.; Correa, J.C.J.; Serrano, R.V.C.; Moreno, G.J.R. Expert control systems implemented in a pitch control of wind turbine: A review. IEEE Access 2019, 7, 13241-13259. [CrossRef]

18. Hansen, A.D. Wind Turbine Technologies. In Wind Energy Engineering, 1st ed.; Elsevier Inc.: Roskilde, Denmark, 2017; pp. 145-160.

19. Eisa, S.A. Modeling Dynamics and Control of type-3 DFIG wind turbines: Stability, Q Droop Function, Control Limits and Extreme Scenarios Simulations. Electr. Power Syst. Res. 2019, 166, 29-42. [CrossRef]

20. Eisa, S.A.; Stone, W.; Wedeward, K. Mathematical modeling, stability, bifurcation analysis and simulations of a type-3 DFIG wind turbine's dynamics with pitch control. In Proceedings of the 2017 Ninth Annual IEEE Green Technologies Conference (Green Tech), Denver, CO, USA, 21 April 2017.

21. Eisa, S.A.; Wedeward, K.; Stone, W. Sensitivity analysis of a type-3 DFAG wind turbine's dynamics with pitch control. In Proceedings of the 2016 IEEE Green Energy and Systems Conference (IGESC), Long Beach, CA, USA, 7 November 2016.

22. Eisa, S.A.; Wedeward, K.; Stone, W. Wind Turbines Control Systems: Nonlinear Modeling, Simulation, two and three time scale approximations, and data validation. Int. J. Dyn. Control 2018, 6, 1776-1798. [CrossRef]

23. Eisa, S.A. Nonlinear modeling, analysis and simulation of wind turbine control system with and without pitch control as in industry. In Advanced Control and Optimization Paradigms for Wind Energy Systems; Springer: Paris, France, 2019; pp. 1-40.

24. Muyeen, S.M.; Hasan-Ali, M.; Takahashi, R.; Murata, T.; Tamura, J.; Tomaki, Y.; Sasano, E. Comparative study on transient stability analysis of wind turbine generator system using different drive train models. IET Renew. Power Gener. 2007, 1, 131-141. [CrossRef] 
25. Yang, B.; Yu, T.; Shu, H.; Zhang, Y.; Chen, J.; Sang, Y.; Jiang, L. Passivity-based sliding-mode control design for optimal power extraction of a PMSG based variable speed wind turbine. Renew. Energy 2018, 119, 577-589. [CrossRef]

26. Liu, J. Intelligent Control Design and MatLab Simulation, 1st ed.; Tsinghua University Press: Beijing, China, 2018.

27. Chamorro, H.R.; Riaño, I.; Gerndt, R.; Zelinka, I.; Gonzalez-Longatt, F.; Sood, V.K. Synthetic inertia control based on fuzzy adaptive differential evolution. Int. J. Electr. Power Energy Syst. 2019, 105, 803-813. [CrossRef]

28. Elfergani, A.; Elsharif, M.A.A.; Hamd, R.H.A.; Saad, S.M.; Naily, N.E.; Mohamed, F.A. Advanced self-tuned pitch angle control based on fuzzy logic for grid connected variable-speed wind turbine system. In Proceedings of the IEEE 9th International Renewable Energy Congress (IREC), Hammamet, Tunisia, 20-22 March 2018.

29. Ayrir, W.; Ourahou, M.; El-Hassouni, B.; Haddi, A. Direct torque control improvement of a variable speed DFIG based on a fuzzy inference system. Math. Comput. Simul. 2018. [CrossRef]

30. Mazouz, F.; Belkacem, S.; Ouchen, S.; Harbouche, Y.; Abdessemed, R. Fuzzy Control of a Wind System Based on the DFIG; Lecture Notes in Networks and Systems; Springer: Cham, Switzerland, 2018; pp. 173-181.

31. Da-Silva, I.N.; Spatti, D.; Andrade, R.; Bartocci, L.H.; Dos-Reis, S.F. Artificial Neural Networks: A Practical Course, 1st ed.; Springer International Publishing: New York, NY, USA, 2017.

32. Zgurovsky, M.Z.; Zaychenko, Y.P. The Fundamentals of Computational Intelligence: System Approach, 1st ed.; Springer International Publishing: New York, NY, USA, 2017.

33. Marugán, A.P.; Márquez, F.P.G.; Perez, J.M.P.; Ruiz-Hernández, D. A survey of artificial neural network in wind energy systems. Appl. Energy 2018, 228, 1822-1836. [CrossRef]

34. Couceiro, M.; Ghamisi, P. Fractional Order Darwinian Particle Swarm Optimization, Applications and Evaluation of an Evolutionary Algorithm, 1st ed.; Springer: Cham, Switzerland, 2016.

35. Kiranyaz, S.; Ince, T.; Gabbouj, M. Multidimensional Particle Swarm Optimization for Machine Learning and Pattern Recognition, 1st ed.; Springer: Cham, Switzerland, 2014.

36. Kesraoui, M.; Lagraf, S.A.; Chaib, A. Aerodynamic power control of wind turbine using fuzzy logic. In Proceedings of the IEEE 3rd International Renewable and Sustainable Energy Conference (IRSEC), Marrakech \& Ouarzazate, Marrakech, Morocco, 10-13 December 2015.

37. Ben-Smida, M.; Sakly, A. Fuzzy pitch angle control for grid connected variable-speed wind turbine system. In Proceedings of the IEEE 7th International Renewable Energy Congress, Hammamet, Tunisia, 22-24 March 2016.

38. Slimen, A.; Tlijani, H.; Dhaoui, M.; Younes, R.B. Intelligent control of wind pump based on PMSG using pitch control. In Proceedings of the IEEE 14th International Multi-Conference on Systems, Signals \& Devices (SSD), Marrakech Tensift El Haouz, Marrakech, Marocco, 30 March 2017.

39. Al-Toma, A.S.; Taylor, G.A.; Abbod, M. Intelligent pitch angle control scheme for variable speed wind generator systems. In Proceedings of the IEEE 52nd International Universities Power Engineering Conference (UPEC), Crete, Greece, 28-31 August 2017.

40. Narasimalu, S.; Chellaiah, B. Pitch angle control for horizontal axis wind turbine: A comparative study. In Proceedings of the IEEE Asian Conference on Energy, Power and Transportation Electrification (ACEPT), Singapore, 24-26 October 2017.

41. Marmouh, S.; Boutoubat, M.; Mokrani, L. MPPT fuzzy logic controller of a wind energy conversion system based on a PMSG. In Proceedings of the 8th International Conference on Modelling, Identification and Control (ICMIC), Algiers, Algeria, 15-17 November 2016.

42. Rajvikram, M.; Renuga, P.; Swathisriranjani, M. Fuzzy based MPPT controller's role in extraction of maximum power in wind energy conversion system. In Proceedings of the International Conference on Control, Instrumentation, Communication and Computational Technologies (ICCICCT), Medea, Algeria, 16-17 December 2016.

43. Zheng, X.; Ding, D.; Li, P. Power Stable Regulation of Direct-Drive Permanent Magnet Wind. Power System Using Pitch and Torque Control; Electrical Engineering Department, Harbin Institute of Technology: Harbin, China, 2015.

44. Cholo, C.A.; Ruiz, J.A.; Guacaneme, J.A. Evaluation of MPPT methods using fuzzy logic applied to a low power wind turbine. In Proceedings of the IEEE Workshop on Power Electronics and Power Quality Applications (PEPQA), Bogota, Colombia, 31 May-2 June 2017. 
45. Pachauri, R.K.; Kumar, H.; Gupta, A.; Chauhan, Y.K. Pitch Angle Controlling of Wind Turbine System Using Proportional-Integral/Fuzzy Logic Controller. Smart Innovation, Systems and Technologies; Springer: New Delhi, India, 2016; pp. 55-63.

46. Tiwari, R.; Ramesh, N.; Sanjeevikumar, P. Fuzzy Logic-Based Pitch Angle Controller for PMSG-Based Wind Energy Conversion System. Advances in Smart Grid and Renewable Energy; Springer: Singapore, 2017; pp. 277-286.

47. Van, T.L.; Nguyen, T.H.; Lee, D.C. Advanced pitch angle control based on fuzzy logic for variable-speed wind turbine systems. IEEE Trans. Energy Convers. 2015, 30, 578-587. [CrossRef]

48. Yang, J.; Song, D.; Han, H.; Tong, P.; Zhou, L. The integrated control of fuzzy logic and model-based approach for variable-speed wind turbine. Turk. J. Electr. Eng. Comput. Sci. 2015, 23, 1715-1734. [CrossRef]

49. Vega, D.C.; Marin, J.A.; Sanchez, R.T. Pitch angle controllers design for a horizontal axis wind turbine. In Proceedings of the IEEE International Autumn Meeting on Power, Electronics and Computing (ROPEC), Ixtapa and Zihuatanejo, Ixtapa, Mexico, 4-6 November 2015.

50. Huang, J.; Jia, H.; Cheng, G. Fuzzy-PI and fuzzy feedforward compound control of variable pitch system. In Proceedings of the 36th Chinese Control Conference, Dalian, China, 26-28 July 2017.

51. Civelek, Z.; Lüy, M.; Çam, E.; Barışçı, N. Control of Pitch Angle of Wind Turbine by Fuzzy PID Controller. Intell. Autom. Soft Comput. 2016, 22, 463-471. [CrossRef]

52. Alarcon, O.F.; Velasquez, B.I.; Hunter, A.R.; Pavez, L.B.; Moncada, R. Hybrid PID-fuzzy pitch control for wind turbines. In Proceedings of the IEEE Conference on Electrical, Electronics Engineering, Information and Communication Technologies (CHILECON), Pucon, Chile, 18-20 October 2017.

53. Baburajan, S. Improving the efficiency of a wind turbine system using a fuzzy-pid controller. In Proceedings of the IEEE Advances in Science and Engineering Technology International Conferences (ASET), Dubai and Sharjah and Abu Dhabi, Abu Dhabi, United Arab Emirates, 6 February-5 April 2018.

54. Aicha, A.; Youcef, M.; Said, H.; Tayeb, A. Intelligent maximum power tracking control of PMSG wind energy conversion system. In Proceedings of the 5th International Conference on Electrical Engineering-Boumerdes (ICEE-B), Boumerdes, Algeria, 29-31 October 2017.

55. Xiao, Y.; Huo, W.; Nan, G. Study of variable pitch control for direct-drive permanent magnet wind Turbines based on fuzzy logic algorithm. J. Inf. Comput. Sci. 2015, 12, 2849-2856. [CrossRef]

56. Beddar, A.; Bouzekri, H.; Babes, B.; Afghoul, H. Experimental enhancement of fuzzy fractional order PI+I controller of grid connected variable speed wind energy conversion system. Energy Convers. Manag. 2016, 123, 569-580. [CrossRef]

57. Elyaalaoui, K.; Ouassaid, M.; Cherkaoui, M. Primary frequency control using hierarchal fuzzy logic for a wind farm based on SCIG connected to electrical network. Sustain. Energy Grids Netw. 2018, 16, $188-195$. [CrossRef]

58. Ponce, P.; Ponce, H.; Molina, A. Doubly fed induction generator DFIG wind turbine controlled by artificial organic networks. Soft Comput. 2017, 22, 2867-2879. [CrossRef]

59. Lee, J.; Kim, Y.S. Sensorless fuzzy-logic-based maximum power point tracking control for a small-scale wind power generation systems with a switched-mode rectifier. IET Renew. Power Gener. 2016, 10, $194-202$. [CrossRef]

60. Civelek, Z.; Lüy, M.; Çam, E.; Mamur, H. A new fuzzy logic proportional controller approach applied to individual pitch angle for wind turbine load mitigation. Renew. Energy 2017, 111, 708-717. [CrossRef]

61. Han, B.; Yang, F.; Xiang, Z.; Zhou, L. Individual pitch controller based on fuzzy logic control for wind turbine load mitigation. IET Renew. Power Gener. 2016, 10, 687-693. [CrossRef]

62. Lasheen, A.; Elshafei, L. Wind turbine collective pitch control via a fuzzy predictive algorithm. Renew. Energy 2016, 87, 298-306. [CrossRef]

63. Yin, X.; Lin, Y.; Li, W.; Gu, Y.; Liu, H.; Lei, P. A novel fuzzy integral sliding mode current control strategy for maximizing wind power extraction and eliminating voltage harmonics. Energy 2015, 85, 677-686. [CrossRef]

64. Saad, L.; Hicham, H.; Khalid, F. Optimal tracking, modeling and control of aerogenerator based on PMSG driven by wind turbine. In Proceedings of the IEEE International Conference on Renewable Energy Research and Applications (ICRERA), Birmingham, UK, 20-23 November 2016.

65. Thanh, S.N.; Xuan, H.H.; The, C.N.; Hung, P.P.; Van, T.P.; Kennel, R. Fuzzy logic based maximum power point tracking technique for a stand-alone wind energy system. In Proceedings of the IEEE International Conference on Sustainable Energy Technologies (ICSET), Hanoi, Vietnam, 14-16 November 2016. 
66. Yin, X.; Zhang, W. Recurrent neural network based adaptive integral sliding mode power maximization control for wind power systems. Renew. Energy 2019. [CrossRef]

67. Hong, C.M.; Chen, C.H.; Tu, C.S. Maximum power point tracking-based control algorithm for PMSG wind generation system without mechanical sensors. Energy Convers. Manag. 2013, 69, 58-67. [CrossRef]

68. Zhang, Y.; Zhang, L.; Liu, Y. Implementation of maximum power point tracking based on variable speed forecasting for wind energy systems. Processes 2019, 7, 158. [CrossRef]

69. Jiao, X.; Meng, W.; Yang, Q.; Fu, L.; Chen, Q. Adaptive continuous neural pitch angle control for variable-speed wind turbines. Asian J. Control 2019. [CrossRef]

70. Tiwari, R.; Krishnamurthy, K.; Neelakandan, R.; Padmanaban, S.; Wheeler, P. Neural network based maximum power point tracking control with quadratic boost converter for PMSG-Wind energy conversion system. Electronics 2018, 7, 20. [CrossRef]

71. Tiwari, R.; Padmanaban, S.; Neelakandan, R. Coordinated control strategies for a permanent magnet synchronous generator based wind energy conversion system. Energies 2017, 10, 1493. [CrossRef]

72. Heshmatian, S.; Khosravi, M.; Khaburi, D.A.; Rivera, M. A wind speed sensorless MPPT-pitch angle control scheme for a WECS using integral sliding mode control and neural network. In Proceedings of the IEEE Southern Power Electronics Conference (SPEC), Puerto Varas, Chile, 4-7 December 2017.

73. Roodsari, B.N.; Macnab, C.J.B.; Nowicki, E.P. A novel adaptive controller using radial basis function neural network for the wind energy conversion system. In Proceedings of the IEEE International Conference on Industrial Technology (ICIT), Toronto, ON, Canada, 22-25 March 2017.

74. Mjabber, E.K.E.; Hajjaji, A.E.; Khamlichi, A. Analysis of a RBF neural network based controller for pitch angle of variable-speed wind turbines. Procedia Eng. 2017, 181, 552-559. [CrossRef]

75. Han, B.; Zhou, L.; Zhang, Z. LIDAR-assisted radial basis function neural network optimization for wind turbines. IEEJ Trans. Electr. Electron. Eng. 2017, 13, 195-200. [CrossRef]

76. Rahman, M.M.A.; Rahim, A.H.M.A. Performance evaluation of ANN and ANFIS based wind speed sensor-less MPPT controller. In Proceedings of the 5th International Conference on Informatics, Electronics and Vision (ICIEV), Dhaka, Bangladesh, 13-14 May 2016.

77. Wei, C.; Zhang, Z.; Qiao, W.; Qu, L. An adaptive network-based reinforcement learning method for MPPT control of PMSG wind energy conversion systems. IEEE Trans. Power Electron. 2016, 31, 7837-7848. [CrossRef]

78. Bagheri, P.; Sun, Q. Adaptive robust control of a class of non-affine variable-speed variable-pitch wind turbines with unmodeled dynamics. ISA Trans. 2016, 63, 233-241. [CrossRef] [PubMed]

79. Dahbi, A.; Nait-Said, N.; Nait-Said, M.S. A novel combined MPPT-pitch angle control for wide range variable speed wind turbine based on neural network. Int. J. Hydrog. Energy 2016, 41, 9427-9442. [CrossRef]

80. Kang, J.; Meng, W.; Abraham, A.; Liu, H. An adaptive PID neural network for complex nonlinear system control. Neurocomputing 2014, 135, 79-85. [CrossRef]

81. Assareh, E.; Biglari, M. A novel approach to capture the maximum power from variable speed wind turbines using PI controller, RBF neural network and GSA evolutionary algorithm. Renew. Sustain. Energy Rev. 2015, 51, 1023-1037. [CrossRef]

82. Wu, S.; Wang, Y.; Cheng, S. Extreme learning machine based wind speed estimation and sensorless control for wind turbine power generation system. Neurocomputing 2013, 102, 163-175. [CrossRef]

83. Mohamed, A.A.A.; Haridy, A.L.; Hemeida, A.M. The whale optimization algorithm based controller for PMSG wind energy generation system. In Proceedings of the International Conference on Innovative Trends in Computer Engineering (ITCE), Aswan, Egypt, 2-4 February 2019.

84. Priyadarshi, N.; Ramachandaramurthy, V.; Padmanaban, S.; Azam, F. An ant colony optimized MPPT for standalone hybrid PV-wind power system with single Cuk converter. Energies 2019, 12, 167. [CrossRef]

85. Saad, N.H.; El-Sattar, A.A.; Marei, M.E. Improved bacterial foraging optimization for grid connected wind energy conversion system based PMSG with matrix converter. Ain Shams Eng. J. 2018, 9, $2183-2193$. [CrossRef]

86. Civelek, Z.; Çam, E.; Lüy, M.; Mamur, H. Proportional integral derivative parameter optimization of blade pitch controller in wind turbines by a new intelligent genetic algorithm. IET Renew. Power Gener. 2016, 10, 1220-1228. [CrossRef]

87. Ebrahim, M.A.; Becherif, M.; Abdelaziz, A.Y. Dynamic performance enhancement for wind energy conversion system using Moth-Flame Optimization based blade pitch controller. Sustain. Energy Technol. Assess. 2018, 27, 206-212. [CrossRef] 
88. Kim, M.K. Optimal control and operation strategy for wind turbines contributing to grid primary frequency regulation. Appl. Sci. 2017, 7, 927. [CrossRef]

89. Daud Pribadi, K.; Danang Wijaya, F. Sarjiya Dynamic response of maximum power point tracking using particle swarm optimization for wind energy conversion system. In Proceedings of the 8th International Conference on Information Technology and Electrical Engineering (ICITEE), Yogyakarta, Indonesia, 5-6 October 2016.

90. Yassin, H.M.; Hanafy, H.H.; Hallouda, M.M. Design and implementation of PI controllers of direct drive PMSG wind turbine system tuned by Linearized biogeography-based optimization technique. In Proceedings of the 42nd Annual Conference of the IEEE Industrial Electronics Society, Florence, Italy, 23-26 October 2016.

91. Behera, S.; Subudhi, B.; Bhusan, B. Design of PI controller in pitch control of wind turbine: A comparison of PSO and PS algorithm. Int. J. Renew. Energy Res. 2016, 6, 271-281.

92. Hodzic, M.; Tai, L.C. Grey predictor reference model for assisting particle swarm optimization for wind turbine control. Renew. Energy 2016, 86, 251-256. [CrossRef]

93. Kasiri, H.; Momeni, H.R.; Abadeh, M.S. Review and improvement of several optimal intelligent pitch controllers and estimator of WECS via artificial intelligent approaches. In Complex System Modelling and Control Through Intelligent Soft Computations, 1st ed.; Springer International Publishing: Cham, Switzerland, 2015.

94. Taher, S.A.; Farshadnia, M.; Mozdianfard, M.R. Optimal gain scheduling controller design of a pitch-controlled VS-WECS using DE optimization algorithm. Appl. Soft Comput. 2013, 13, 2215-2223. [CrossRef]

(C) 2019 by the authors. Licensee MDPI, Basel, Switzerland. This article is an open access article distributed under the terms and conditions of the Creative Commons Attribution (CC BY) license (http://creativecommons.org/licenses/by/4.0/). 